\title{
AUTONOMÍA, INSURGENCIA \\ Y OLIGARQUÍA: LAS PROVINCIAS \\ INTERNAS Y LA FORMACIÓN \\ DE LOS ESTADOS SEPTENTRIONALES
}

\author{
Alonso Domínguez Rascón \\ Universidad Autónoma de Ciudad Juárez
}

Wettie Lee Benson argumentó que el sistema federal 1 mexicano surgió gradualmente y no por una decisión dada en 1823 sin ningún antecedente. Para ella se da en un largo tiempo y se desarrolla aceleradamente bajo la Constitución de Cádiz de 1812 por medio del establecimiento de las diputaciones provinciales, siendo estos cuerpos a los que atribuyó el elemento esencial de la conformación del federalismo mexicano. ${ }^{1}$ También argumentó que México compartía una cultura política general con España y que esa cultura política compartida sentó las bases para el desarrollo político y constitucional de México. ${ }^{2}$ Por su parte Hira de Gortari

Fecha de recepción: 10 de agosto de 2015

Fecha de aceptación: 7 de diciembre de 2015

${ }^{1}$ Véase Benson, La diputación provincial.

2 Rodríguez, "Interpretaciones generales", p. 206. También GuedeA, "La historia política”, pp. 43-45. 
afirma que una parte fundamental del diseño territorial de la federación empezó a funcionar a partir de las intendencias, algunas de las cuales se convirtieron en los futuros estados de la federación o parte de ellos. ${ }^{3}$ Para Antonio Annino fueron las oligarquías territoriales las que suscribieron el pacto interoligárquico para conformar la nación por medio de una federación. ${ }^{4}$ De esta manera México es producto de una revolución aristocrática y se remonta en su explicación a los orígenes del régimen de pacto, el cual para él constituye ese espacio que se da entre la norma escrita y la norma consuetudinaria. ${ }^{5}$ Siguiendo a Annino, Pérez Herrero asegura que si los antiguos territorios no se fragmentaron como los del virreinato del Perú fue debido al pacto interoligárquico. ${ }^{6} \mathrm{Sin}$ dejar de reconocer la importancia que tienen las propuestas anteriores como elementos explicativos de la conformación federalista de México sostenemos que el elemento explicativo central del federalismo septentrional es el autonomismo, en la mayoría de los casos anclado en los ayuntamientos, asiento por excelencia de las oligarquías norteñas. Que las oligarquías se unan para suscribir el pacto en función de sí mismas parece una postura general y unívoca y no nos explica los antagonismos tan marcados y enconados existentes entre ellas ya que se ha dejado de lado. El autonomismo es el sustento de esas oligarquías, es lo que les da fuerza, pero también en esas posiciones autonómicas se expresan el conflicto y la divergencia presentes entre grupos de poder, por eso las llamamos oligarquías autonómicas.

3 Gortari, “La organización política”, p. 52.

4 Véase Annino, "El pacto y la norma".

5 GuedeA, “La historia política”, pp. 53-54.

6 Pérez Herrero, “El México borbónico”, p. 149. 
Las oligarquías norteñas que llevaron a cabo la tarea de la formación de los estados estaban compuestas por ricos mineros, comerciantes o grandes hacendados. En el norte el pacto interoligárquico funcionó, por sus posturas autonómicas, primero fraccionando los conglomerados territoriales. Así, de los dos bloques de las Provincias Internas (Oriente y Occidente) siguieron cuatro estados y por último siete estados y un territorio para sumarse al pacto nacional. ¿Por qué esas oligarquías proceden de esa manera? No hay una única respuesta, las causas son multifactoriales, pero una de las principales es la autonómica. El ejercicio de esa autonomía norteña es complejo porque no está encerrada en una sola delimitación territorial; políticamente tiene diferentes planos o niveles. Los diputados de las Provincias Internas se desenvolvían cuando menos en tres perspectivas de autonomía: el local relativo a su pueblo, ciudad o ayuntamiento, el provincial y el multiprovincial; en este último encontramos los grandes bloques de Occidente y Oriente. Indudablemente en ese mismo orden enunciado van su fuerza y determinación.

Héctor Hernández advierte para la provincia de SonoraSinaloa que el sentir autonomista de los notables de Sonora se tradujo en la demanda de autogobierno. Por eso vieron en el federalismo un sistema político que les daba el control sobre sus espacios de poder. ${ }^{7}$ Los posicionamientos de autogobierno localista y los conflictos entre las oligarquías en las Provincias Internas parecen desdibujar los rasgos y posturas autonómicas provinciales y multiprovinciales, pero están presentes en ellas y se expresan de diferentes maneras. Pero,

7 Hernández, “Las provincias”, p. 559. 
¿por qué son más fuertes las localistas? En general Annino comenta que la proliferación de estados en los años veinte del siglo xix, mucho más numerosos que las unidades administrativas originales, indica que no había una identidad territorial definida. ${ }^{8}$ Si nos ceñimos a eso sería aún más aplicable a las Provincias Internas por sus múltiples cambios de estatus y composición territorial. Contrasta lo anterior con la afirmación de Estrada Michel, quien dice que las Provincias Internas poseían una identidad política propia. ${ }^{9}$ No pensamos que sea falta de identidad la respuesta, sino que está en la conformación histórica de las Provincias Internas.

Vistos los puntos anteriores, el asunto es ver cómo se agregaron las Provincias Internas de Occidente y Oriente al pacto de creación de la federación mexicana a partir de sus posturas autonómicas. También por qué siendo una jurisdicción autónoma en diversos momentos de su existencia no alcanzó a constituirse en una nación independiente. Rafael Estrada Michel ve en la labor legislativa del diputado por Coahuila, Miguel Ramos Arizpe, en las Cortes doceañistas, no solo autonomismo sino separatismo. Por su parte, el diputado de Nuevo México, Pedro Bautista Pino, en una sesión de noviembre de 1812, habla sobre su provincia como algo muy ajeno y extraño al virreinato. Ramos Arizpe va más allá y niega cualquier lazo con lo mexicano, de sí mismo dice que no es mexicano sino comanche. ${ }^{10}$ Para Estrada resulta evidente que en ese primer momento parlamentario la intención del diputado era escindir a las

\footnotetext{
8 Annino, "El pacto y la norma”, p. 7.

9 Estrada, Monarquía y nación”, pp. 596-597.

10 Estrada, Monarquía y nación, pp. 596-597.
} 
Provincias Internas de Oriente del gobierno de la Nueva España. Ramos Arizpe logra que las Cortes aprueben un gobierno superior en todos sus ramos para las cuatro Provincias de Oriente y el establecimiento de una audiencia. ${ }^{11}$ Era una postura autonómica multiprovincial que bregaba porque todas las Provincias de Oriente se mantuvieran como una sola unidad política administrativa y territorial; lo mismo sucedía en las Provincias de Occidente.

\section{II}

Al final de la época colonial existían en el septentrión las Provincias Internas de Occidente y las de Oriente. Las primeras comprendían las provincias de Sonora-Sinaloa, Nueva Vizcaya (los actuales estados de Chihuahua y Durango) y Nuevo México. La segunda, Coahuila, Texas, Nuevo Reino de León y Nuevo Santander (Tamaulipas). Primero veremos el carácter jurisdiccional de dichas entidades, el papel que desempeñaron en la revolución de independencia de México, para después pasar a la formación de los estados norteños. En cuanto a la guerra de independencia la historiografía regional ha registrado acciones aisladas que fueron rápidamente controladas o conspiraciones que no prosperaron. Por otra parte, la historiografía estadounidense vislumbra en las Provincias Internas de Occidente una posición decididamente monarquista. En general el papel que desempeñaron en el refuego insurgencia-contrainsurgencia todavía no es muy claro. Lo mismo ocurre en relación con la participación de las Provincias Internas en la formación de la nación.

11 Véase Estrada, Monarquía y nación, pp. 599-600. 
Para comprender la dinámica histórica del septentrión es necesario entender qué era la Comandancia General de las Provincias Internas. ${ }^{12}$ Fue creada en 1776 con José de Gálvez como su principal impulsor. Dado el nombre la jurisdicción ha sido tratada como una instancia meramente militar, por lo que se ha soslayado su aspecto y función político y administrativo. En un principio fue creada con un carácter totalmente independiente del virreinato y al comandante general se le dotó con todas las prerrogativas de un virrey. Carlos III decretó sobre las facultades de su titular:

[...] en todas las disposiciones y providencias de vuestro Govierno y Capitanía General dependeréis solo de mi Real Persona y de las órdenes que Yo os dirijiere por la vía reservada de Yndias [...] Así mismo declaro que en las providencias de vuestro govierno haveis de ejercer la superintendencia general de mi Real Hacienda con inmediata dependencia de mi Real Persona [...] Os concedo igualmente las amplias facultades que por las mismas Leyes de Yndias competen a los virreyes y governadores Pretoriales en el exercicio de mi Real Patronato. ${ }^{13}$

Era precisamente la figura de la nueva jurisdicción un virreinato con nombre de Comandancia General. Se le ordenaba al comandante general informar de lo más importante al virrey para que en caso de que necesitara apoyo ya estuviera éste prevenido. Pero a través del tiempo la jurisdicción

12 Weber, Bárbaros, pp. 156-161. Para la política militar de guerra contra los apaches véase este autor.

13 Véase la instrucción y decreto de creación de la jurisdicción: AGN, $R C$, 108. ff. $178-188 \mathrm{v}$. 
sufrirá una serie de reorganizaciones en cuanto a las facultades y carácter de su máxima autoridad, el comandante general, y en su composición territorial, algunas veces subdividiéndola, otras ocasiones agregándole provincias o quitándoselas. A lo anterior se debe que en la historiografía se le haya dado más peso a las etapas de dependencia borrando prácticamente las de autonomía.

Las decisiones tomadas por la corona en cuanto a las múltiples modificaciones territoriales y atribuciones político administrativas de los comandantes generales impidieron que el proyecto obtuviera mayor fortaleza. Asimismo, éstos tuvieron en los virreyes de la Nueva España a poderosos enemigos. Si algo puede definir en mejor forma la relación histórica de las Provincias Internas, por medio de su Comandancia General con el virreinato de la Nueva España, es el conflicto. Los virreyes, no todos, con frecuencia se embarcaron en una cruzada para hacer depender de nuevo las Provincias Internas a su mando, y los comandantes generales por mantener la autonomía. Así que la jurisdicción atravesó por etapas de autonomía y dependencia respecto al virreinato. En el tiempo de su existencia ocuparon el mando con todas las facultades originales Teodoro de Croix (1776-1783) y Felipe de Neve (1783-1784). Después se decreta, en 1785, la dependencia al virreinato, la cual tiene lugar con el comandante Jacobo de Ugarte y Loyola (1784-1790) y Antonio Cordero (1790-1791). Con Pedro de Nava (1791-1802), la corona restableció la autonomía de la Comandancia General en 1792 y prosiguió con Nemesio Salcedo (1802-1813). Con Bernardo Bonavía y Zapata (1813-1817), fue retirada de nuevo la autonomía de la jurisdicción en 1813 y así continuó con el último comandante 
general, Alejo García Conde (1817-1822).${ }^{14} \mathrm{Al}$ compás de los cambios de las facultades de los comandantes generales también se suscitan modificaciones en su ordenación geoespacial, al grado de tener cinco composiciones territoriales a lo largo de su existencia.

1. Al crearse en 1776 la jurisdicción se componía de las provincias de: Californias, Sonora-Sinaloa, Nueva Vizcaya, Nuevo México, Coahuila y Texas. ${ }^{15}$

2. En 1785 se da la primera modificación y el virrey Bernardo de Gálvez la divide en tres comandancias agrupadas como sigue: a) Sonora-Sinaloa, Baja California y Alta California, b) Nueva Vizcaya y Nuevo México y c) Texas y Coahuila, agregándoles el Nuevo Reino de León y Nuevo Santander. La primera comandancia quedó bajo las órdenes de Jacobo de Ugarte y Loyola, a quien se le dio autoridad limitada sobre los comandantes de las otras dos jurisdicciones, Antonio Rengel y Juan de Ugalde respectivamente. ${ }^{16}$

3. El siguiente virrey, Manuel Antonio Flores, no vio funcional la división que había impuesto el fallecido Gálvez y en 1787 las dividió en dos bloques agrupados como sigue: a) Nueva Vizcaya, Nuevo México, Sinaloa, Sonora, Baja California y Alta California; la jurisdicción quedó denominada como Provincias Internas de Occidente. b) Coahuila, Texas,

14 Véase Domínguez, "Estado, frontera”; Antonio Cordero y Jacobo Ugarte y Loyola ocuparon el cargo como interinos.

15 AGN, $R C, 108$, ff. 178-188v.

16 AGN, PI, 129, ff. 68-95v. Instrucción formada en virtud de real orden de S. M. que se dirige al señor comandante general de Provincias Internas, D. Jacobo Ugarte y Loyola, para gobierno y puntual observancia de este superior jefe y de sus inmediatos subalternos (1786). También BANCROFT, History, pp. 639-640, y Vizcaya, En los albores, p. xiv. 
Nuevo Reino de León y Nuevo Santander bajo el nombre de Provincias Internas de Oriente. Las de Occidente quedaron bajo las órdenes de Ugarte y las de Oriente de Ugalde, con autoridad y atribuciones únicamente sobre lo militar, totalmente independientes entre sí pero sujetas al virrey. ${ }^{17}$

4. En 1792 se le da de nuevo autonomía a la Comandancia General respecto al virreinato y se le regresa la jurisdicción territorial primigenia, pero las Californias, junto con las provincias de Nuevo Reino de León y Nuevo Santander, dependen otra vez del virreinato. ${ }^{18}$

5. En 1804, por real decreto se ordena dividirla nuevamente en dos jurisdicciones y a sus comandantes se les hace dependientes del virrey, pero no se lleva a cabo. En 1811 las Cortes retoman el decreto anterior y ordenan al virrey se lleve a efecto; finalmente se concreta en $1813 .{ }^{19}$

Desde 1768, Gálvez y el virrey Croix, al elaborar el plan de la creación de la Comandancia General, propusieron para su mayor consolidación el establecimiento de una casa de moneda. En el numeral $6^{\circ}$ del decreto fundacional se especificaba lo siguiente:

Respecto de que para evitar los graves perjuicios que experimentan los havitantes de aquellas provincias y los que sufre mi real erario por la falta de dinero en el comercio de ellas: he resuelto que se establezca en Sonora una casa de moneda capaz

17 Flores, Instrucción, p. 119, citado en O'Gorman, Historia de las divisiones, p. 17. También Almada, Resumen de historia, p. 12; Vizcaya, En los albores, p. xv.

18 Vizcaya, En los albores, p. xv. También O'Gorman, Historia de las divisiones, pp. 18-19.

19 Véase Cavazos, Breve historia, p. 86, citado en Morado, "Nuevo León durante", imagen 112. 
de labrar la necesaria al giro y socorro de aquellos Países os mando que de acuerdo con el yntendente la hagáis fabricar y erigir en el propio Pueblo de Arizpe lo más brebe que sea posible y con la misma ordenanza que se gobierna la de México, de la que a su tiempo se embiarán los oficales, cuños ynstrumentos y demás útiles precisos. ${ }^{20}$

En 1787 Ugarte y Loyola, en un documento titulado Propuesta para la creación de una real audiencia en Provincias Internas, decía al ministro de Indias que esperaba tener consolidada la facultad de Intendencia de Real Hacienda con instrucciones terminantes para su mejor desempeño y consiguiente a ella la real casa de moneda, casa de quintos con su pagaduría formalizada en tesorería. Lo anterior redundaría en una mejor administración, beneficio y cobro por la circulación de suficiente moneda, la cual faltaba para los objetos más urgentes al servicio y la prosperidad del comercio. ${ }^{21}$

Sin embargo, desde sus inicios el proyecto contó con férrea oposición. El Consulado de Comerciantes de la Ciudad de México se opuso determinantemente y utilizó su poderosa influencia ante la burocracia imperial para que el proyecto no prosperara. En franca protección del Consulado, el fiscal de la Real Audiencia y el superintendente de la Casa de Moneda, ambos de la capital, se pronunciaron contra el proyecto. ${ }^{22}$

Junto con la casa de moneda, otro aspecto nodal era el del establecimiento de la capital. Bernardo García Martínez ha

20 AGN, $R C, 108$, f. 180v.

21 AGN, PI, 254, ff. 79-79v., carpeta 2a , Propuesta para la creación de una real audiencia en Provincias Internas ( 2 de junio de 1787).

22 Río, La aplicación regional, pp. 171-173. 
señalado la carencia de una capital para las Provincias Internas que pudiera efectivamente funcionar como tal. ${ }^{23} \mathrm{Gra}-$ ves errores de inicio sobre la decisión del lugar y la naturaleza del establecimiento de la capital se convirtieron en otro aspecto que retrasó la consolidación e institucionalidad de la naciente jurisdicción. En el decreto e instrucción al comandante general se razonaba de la siguiente manera: "Con la mira de que os halléis siempre en proporción de ocurrir personalmente, o con oportunas providencias a los parajes más distantes de vuestro govierno estableceréis por ahora la capital de vuestra residencia en el Pueblo de Arispe situado sobre el Río Sonora y cercano a la frontera de aquella provincia por estar casi a igual distancia de la Nueva Vizcaya y Californias [...]" ${ }^{24} \mathrm{El}$ "por ahora" nos muestra lo transitorio en la selección primaria de Arizpe como capital; la razón es que Gálvez deseaba fundar Carlópolis, en honor a Carlos III, como una gran capital más hacia el septentrión en la zona de la conjunción de los ríos Gila y Colorado. ${ }^{25} \mathrm{La}$ decisión se había labrado pensando en las necesidades del momento, como la de poder establecer una ruta terrestre con la Alta California y apoyarla en caso de cualquier emergencia militar. Gálvez pensaba en la consolidación de la ocupación de dicha provincia ya que si los españoles habían llegado a esas latitudes se debía solo a la determinación de él de colonizarlas. Además, se le veía como una zona estratégica ya que se pensaba que las potencias extranjeras de un momento a otro intentarían apoderarse de ella.

23 García, “El espacio”, pp. 34-35.

24 AGN, $R C, 108$, f. 180.

25 Río, La aplicación regional, p. 122. 
Uno de los argumentos más fuertes para la creación de la jurisdicción había sido la gran distancia de la Ciudad de México a las Provincias Internas y por ende la incapacidad del virrey para atenderlas de forma adecuada. En un inicio se había pensado que solo las Californias, Sinaloa, Sonora y Nueva Vizcaya compondrían la Comandancia General, pero en el decreto se agregaron también las de Nuevo México, Texas y Coahuila. Así, las poblaciones más lejanas en Texas estaban a una enorme distancia de Arizpe y en ese sentido resultaba incongruente fijar la capital en Sonora.

El comandante general Ugarte presionó para que la Comandancia General se trasladara a un lugar más geocéntrico y equidistante de la jurisdicción y propuso para ello la Nueva Vizcaya. Con las muertes de José de Gálvez en 1787 y Carlos III en 1788 se logrará tal proyecto y al restaurarse la autonomía a la jurisdicción en noviembre de 1792 se fijará la Villa de Chihuahua como sede de su máxima autoridad. Desde esa fecha, con el comandante general Pedro de Nava, hasta 1813, en que deja la titularidad Nemesio Salcedo, Chihuahua será la capital de las Provincias Internas y se caracterizará como una época de relativa paz y prosperidad. La pregunta es, ¿ funcionó Chihuahua cómo capital de todo el conjunto territorial? Más adelante retomaremos esta pregunta.

Un tercer elemento que autoridades y sociedad septentrional buscaron establecer en el septentrión fue una real audiencia. Estos cuerpos no solo atendían asuntos judiciales sino también aspectos relacionados con la problemática gubernamental y administrativa. En especial el fiscal de lo civil era consultado por los virreyes para todos los problemas relacionados con la administración civil y financiera. Debido a sus 
funciones políticas la Real Audiencia de México era definida como el "gabinete de ministros del virrey". ${ }^{26}$ Esa visión de las audiencias como una herramienta de poder, gobierno en general y ordenador social era sabida por las autoridades y sociedad de las Provincias Internas y en muchas ocasiones pidieron y hasta exigieron su establecimiento.

El primer comandante general, Teodoro de Croix, inició las gestiones para el establecimiento de una real audiencia. En junio de 1778 planteó la necesidad de su creación, la cual proponía fuera de dimensiones reducidas. Argumentó que el traslado a la Real Audiencia de Guadalajara era difícil por la distancia y las habituales hostilidades de los grupos étnicos. ${ }^{27}$ Croix, como muchos otros borbones ilustrados, tenía la visión de que el mejoramiento en la impartición de justicia era muy importante en el ejercicio del buen gobierno. ${ }^{28}$ Pero fue su sucesor, Felipe de Neve, quien con mayor vehemencia planteó la necesidad de que la corona autorizara una real audiencia en el septentrión y en 1783, en un informe, reforzó la propuesta al rey. ${ }^{29}$

En su solicitud Neve dijo que la Real Audiencia contribuiría a mejorar la constitución de la jurisdicción y a su prosperidad, en especial en cuanto a la Real Hacienda. En la visión de Neve la Real Audiencia era fundamental para el proceso de institucionalización y consolidación de la nueva jurisdicción, pero además era importante para su definición

${ }_{26}$ Pietschmann, Las reformas borbónicas, p. 81.

${ }^{27}$ Navarro, Don José de Gálvez, p. 314.

${ }_{28}$ Cutter, "La Real Audiencia", p. 281.

29 AGN, PI, 254, ff. 79-79v. También AGN, PI, 254, ff. 26, 32, numeral 10, Informe general del comandante general de Provincias Internas Dn. Jacobo Ugarte y Loyola, diciembre 1 de 1787. 
política y territorial. ${ }^{30}$ Bajo esa percepción la Real Audiencia se convertiría en un órgano constitutivo y constituyente no solo del orden judicial sino también político y formativo de identidad política. Por lo tanto, en una instancia territorial y socialmente integradora de la jurisdicción. En marzo de 1785 el proyecto fue aprobado por el rey y se previno al comandante general del momento, José Antonio Rengel, se fuera poniendo en ejecución, pero no se concretó. En 1787 Ugarte, sucesor de Neve, insistió ante Gálvez en la necesidad de hacer efectivo el proyecto del tribunal dado "[...] el beneficio que resulta de la más recta, metódica y pronta administración de justicia de lo mucho que contribuye a estos fines un Tribunal que franquea para exigirlo en la capital de estas Provincias sin dispendio del Real Herario". ${ }^{31}$ En cuanto a su planta, número de ministros y cualidades de su regencia, Ugarte proponía que fuera igual a la que se acababa de establecer en Caracas. Propuso para regente al asesor y auditor de guerra de la Comandancia General, Pedro Galindo Navarro. ${ }^{32}$ Sin embargo, el proyecto de la Real Audiencia nunca se concretó.

Por otra parte, como ya vimos con Nava, se le restituyó a la jurisdicción su independencia respecto al virreinato y en medio de las precariedades que sufría por las hostilidades con los grupos étnicos, la escasez de población y su dispersión, la Comandancia General fue una instancia integradora y de institucionalidad fundamental del septentrión, además

\footnotetext{
30 Cutter, “La Real Audiencia”, pp. 279 y 282.

31 AGN, PI, 254, ff. 79-80.

32 AGN, PI, 254, ff. 79-80v.
} 
de una fuente muy importante de autonomía, identidad política, y dio estabilidad a la jurisdicción.

La lejanía con los grandes centros de poder del virreinato o de acceso a provisiones, como la Ciudad de México o los puertos, puede traducirse en precariedad para la jurisdicción pero también en un aspecto que hasta ahora no se ha calculado y es muy importante: la autonomía militar y política. Otro elemento especial a considerar en la institucionalidad y el poder que llegó a adquirir la Comandancia General no se da solo en su propio instituto; como todas las demás instancias del imperio, se sustenta en las demás instituciones presentes y en el consenso de los habitantes de su jurisdicción. Así, la sociedad septentrional veía en la Comandancia General una instancia de verdadero orden y sobre todo de protección, no solo ante las etnias hostiles sino también ante la cada vez más palpable amenaza anglosajona. Por otra parte, otras instancias de apoyo fundamental eran los ayuntamientos, en los que también se sustentaba gran parte del ejercicio político administrativo. Esencial en el gobierno de la Comandancia General fue el poderoso ayuntamiento de la Villa de Chihuahua, compuesto por una sobresaliente cúpula de mineros, comerciantes y hacendados. Asimismo, la creación de las milicias regladas y la colonización multiétnica habían sido programas a los que apostó la Comandancia General, sobre todo en este último aspecto con gran éxito. ${ }^{33}$

Características fundamentales del septentrión que nos ayudan a explicar por qué el movimiento insurgente en el virreinato no solo no tuvo eco en las Provincias Internas sino que además se convirtieron en uno de los principales

33 Véase Domínguez, “Estado, frontera”, pp. 25-73, 95-113. 
bastiones contrainsurgentes, principalmente la provincia de mayor poder de la Comandancia General: la Nueva Vizcaya.

\section{III}

Visto el carácter de la jurisdicción vamos a centrarnos en los aspectos de la insurgencia. En la historiografía regional se ve el empeño por escarbar y encontrar elementos que demuestren que la sociedad septentrional era independentista, pero solo se han encontrado acciones aisladas y conspiraciones que no prosperaron. Como contraparte de la historiografía mexicana, la estadounidense vislumbra en las Provincias Internas de Occidente una posición monarquista. Hace ya tiempo el historiador estadounidense Oakah Jones se preguntaba: ¿por qué la Nueva Vizcaya apoyó firmemente la causa realista durante el periodo de la independencia mexicana?, ¿por qué siendo esta provincia la más importante en la frontera permaneció leal a la corona española, la Junta Central, las Cortes o la causa realista durante la guerra de independencia? A continuación enumeró una lista de factores explicativos de sus preguntas: 1) Los oficiales, funcionarios y la mayoría de los miembros de los ayuntamientos eran devotos del orden establecido y defendieron la provincia de la agitación revolucionaria; 2) Los intereses económicos de mineros, hacendados, comerciantes y artesanos estaban a favor de la corona debido al apoyo, concesiones y favores especiales durante los últimos años del régimen borbón; 3) No había rivalidades como el intenso choque entre criollos y peninsulares en el centro de la Nueva España, por lo tanto, no había sentimientos de frustración que llevaran a antagonismos en Nueva Vizcaya. En los censos, aunque 
se indicaba la clase de los individuos, no se refleja el uso del término criollo, se usa el de europeo para los nacidos tanto en América como en España. Más aún, en Nueva Vizcaya, los criollos ocupaban altos puestos en el gobierno civil y eclesiástico. Asimismo, en los ayuntamientos de Chihuahua y Durango disfrutaban de considerable poder y prestigio. 4) No había clima revolucionario o evidente liderazgo, únicamente dos pronunciamientos aislados (Porras en 1811 y Trespalacios en 1814) por la independencia, los cuales fueron rápidamente suprimidos por las autoridades; 5) Las distancias y dispersión de la población en una enorme región eran factores que actuaban en contra; 6) En Nueva Vizcaya no había muchos extranjeros que con sus ideas pudieran alterar el orden, como en Texas o Nuevo México; 7) Los conceptos de la Ilustración no tuvieron en Nueva Vizcaya el mismo grado de impacto que se dio entre los vecinos educados de la Ciudad de México y áreas aledañas. ${ }^{34}$

La situación es que las Provincias Internas viven un momento histórico diferente al del virreinato. Vamos a esbozar también en siete puntos esas diferencias:

1) Al momento de estallar la insurgencia en el virreinato se vive en las Provincias Internas una relativa paz después de lustros de guerra con los grupos étnicos hostiles. En el último tercio del siglo XviII la escalada de la guerra contra la sociedad colonial perpetrada por los indios hostiles toma proporciones formidables y nunca vistas en cuanto a su fuerza y organización. Mediante coaliciones multiétnicas y una nueva cultura guerrera los naturales llevan

34 Jones, Nueva Vizcaya, pp. 225-226. También véase Weber, La frontera norte. 
a la sociedad septentrional a una grave crisis. A la guerra se añadieron sucesivas crisis productivas, hambrunas y epidemias, por lo que la muerte se convirtió en una constante y el precio de la vida en un máximo tesoro. La comunicación hacia otros lugares de la Nueva España se tornó en extremo complicada por los ataques y asaltos en todo tipo de caminos. El fuego en bosques, sementeras, caminos, viviendas, construcciones religiosas y militares se volvió habitual en el paisaje. Las fogatas para producir señales de humo entre indios rebeldes, la quema de prisioneros, los muertos en la guerra o por enfermedades epidémicas, eran una constante y la pólvora se convirtió en un bien preciado para todos. ${ }^{35}$ La salida de los funcionarios borbones no va a ser la militar sino el pacto con los indios bajo la máxima de que era mejor una mala paz que los esfuerzos de una buena guerra. La paz se logró con mucho esfuerzo y desgaste de recursos humanos y materiales.

Así que al estallar la insurgencia tenemos una sociedad anhelante de paz, pero las incursiones de indios hostiles, sobre todo de apaches y comanches, se siguen presentando y existe el temor de una nueva escalada de la guerra. Por ende militares y sociedad septentrional viven a la expectativa y con la preocupación de que las hostilidades se reactiven en gran proporción y en cualquier momento.

2) La sociedad septentrional también vive con la gran preocupación de la frontera; desde que Estados Unidos obtuvo su independencia se le ve como una gran amenaza, sobre todo cuando se quedó con la Luisiana en 1804, y en muchas ocasiones se piensa que una invasión es inminente.

35 URÍAs, “Rarámuris”, p. 91. 
3) Para protección se crearon las milicias regladas que relativamente resolvían el problema de la creación de un ejército que la precaria economía del imperio no se podía dar el lujo de solventar. La pertenencia a las milicias en ciertos aspectos y medidas permitió romper la rígida organización social jerarquizada. Los criollos encontraron en la habilitación de milicias, por medio del padrinazgo, el grado de capitanes, mayor estatus social y el aumento de prestigio personal. Otro aspecto muy importante es que se les concedía el fuero militar y con ocho años de servicio ininterrumpido podían obtener el hábito de las órdenes militares. ${ }^{36}$ Así podían acceder a los círculos gubernamentales, conseguir conexiones políticas, financieras y obtener rango cuasi oficial en la burocracia imperial. ${ }^{37}$

4) Para fortalecer la colonización y presencia secular los borbones crearon un programa de colonización bajo el paradigma de las colonias de Sierra Morena en Andalucía. Ante la escasez de población las nuevas colonias fueron de carácter miliciano, y multiétnicas al fundarse con peninsulares, criollos, indios, castas y negros. Así la nueva colonización implicó que todos sus miembros, además de su situación étnica, obtuvieran la condición de colonos originarios o fundadores, propietarios de la tierra y exentos de impuestos, todos bajo el mismo estatus. Las milicias y el régimen de las colonias militares contribuían a la conformación de una sociedad menos jerarquizada.

36 AHMJ, CGPR, c. 2, exp. 58, f. 21, Ordenanza provisional para gobierno del Cuerpo de Dragones Provinciales de San Carlos, título 9, art. 7. 37 González Alzate, "Las milicias y la preservación”, p. 9. 
5) Todo lo anterior propiciaba que rivalidades entre sectores y grupos de poder, así como entre criollos y peninsulares, fueran atemperadas; la causa del enemigo común, más las relaciones de parentesco, económicas y de propiedad, hacían que las diferencias, si no eran borradas, sí desdibujadas. Más aún entre la escasa población de criollos y peninsulares. El proyecto reformador borbón para el septentrión implicó la creación del sujeto ideal de la frontera esbozado en tres dimensiones: laico, propietario y miliciano. ${ }^{38}$

6) El proyecto borbón defensivo del septentrión aumentó y profesionalizó las tropas en las Provincias Internas. Los soldados presidiales y de las compañías volantes contaban con la disciplina, entrenamiento y el factor fundamental de la experiencia en combate, a diferencia de los ejércitos insurgentes, indisciplinados y sin experiencia. Lo mismo podemos decir de las milicias del virreinato de la Nueva España, las cuales - a diferencia de las del septentrión - tampoco contaban con experiencia. En ese sentido y con esos recursos militares los comandantes de las Provincias Internas de Occidente sellaron la entrada a los insurgentes a la Nueva Vizcaya creando y emplazando el ejército de Tierra Adentro en Sombrerete, Zacatecas. ${ }^{39}$

7) Para evitar el surgimiento de rebeliones y progreso de conspiraciones dentro de las provincias crearon las Juntas de Seguridad en los pueblos y emitieron bandos con penas muy rigurosas, lo cual resultó ser muy efectivo. ${ }^{40}$

\footnotetext{
38 Domínguez, "Estado, frontera”, pp. 25-57.

39 SÁnchez de TAgle, Insurgencia y contrainsurgencia, pp. 94-130.

40 Domínguez, “Estado, frontera”, pp. 272-276.
} 
Recibidas las noticias en Chihuahua de las derrotas de los contrainsurgentes en la toma de la Alhóndiga de Granaditas y en el Monte de las Cruces, el comandante general, Nemesio Salcedo ordenó que se concentraran en la capital fracciones de las tropas de todas las compañías presidiales, volantes y milicianos con el propósito de defender las Provincias Internas. En ese momento la parte norte de la provincia de la Nueva Vizcaya (lo que actualmente es el estado de Chihuahua) contaba con 757 soldados en las primeras y 531 en las segundas para un total de 1288 elementos regulares más los milicianos. Con parte de estas fuerzas más voluntarios de Parral, Guejuquilla, Cusihuiriachi, Valle de los Olivos y una sección de indios flecheros tarahumaras se constituyó una sección del ejército de Provincias Internas fuerte en 900 plazas. Quedó bajo las órdenes del teniente coronel José Manuel de Ochoa, quien fue apoyado por los capitanes Pedro María Allande, Pedro Ruiz de Larramendi y Facundo Melgares. Desplazándose Ochoa al sur otros contingentes de soldados regulares y milicianos de la parte sur de la Nueva Vizcaya (hoy Durango), comandados por el gobernador intendente Bernardo Bonavía y el teniente coronel José López, reforzaron los mandados por Salcedo. Más tarde, cuando los insurgentes invadan las Provincias Internas de Oriente, se enviarán más contingentes al sur para reforzar a las tropas ya mencionadas bajo el mando del teniente coronel Alberto Máynez, ${ }^{41}$ fuerzas que constituyeron el ejército

\footnotetext{
${ }^{41}$ Véase Almada, El periodo de la independencia, pp. 19-20. Compañías presidiales: Janos, 133 soldados; Galeana, 99; Carrizal, 95; San Elizario, 92; Ojinaga, 97; Coyame, 53; San Jerónimo, 88; Chihuahua, 100. Compañías volantes: Primera en Guejuquilla, 142 soldados; Segunda en Namiquipa 107, Tercera en San Francisco de Conchos; 145 y Cuarta en San Pablo, 137.
} 
de las Provincias Internas o de Tierra Adentro. Salcedo dio el comando general de esas tropas a Bonavía.

El 2 de noviembre de 1810 las fuerzas comandadas por el coronel insurgente Rafael Iriarte entraron a Zacatecas. Les asignó a sus capitanes Baltasar Musiño, José Mariano Sotomayor, Juan Parada y Francisco Bustos preparar la ofensiva contra las fuerzas de las Provincias Internas y un posible avance por el Camino Real de Tierra Adentro para tomar Durango, pero el plan no prosperó. San Luis Potosí había quedado desguarnecido y los rebeldes locales se apoderaron de la plaza, lo cual le resultó muy atractivo a Iriarte ya que decidió acudir en persona a la ciudad, a la cual se dirigió el 14 de noviembre. El 3 de diciembre de ese año un mozo que pasaba por la hacienda de la Sauceda se encontró un ejército que le dijeron estaba constituido por 2200 hombres $\mathrm{y}$ muchos indios flecheros venidos desde Chihuahua para reconquistar Zacatecas. ${ }^{42}$ Sin embargo, emplazar el ejército de Tierra Adentro en la jurisdicción vecina de Zacatecas no tenía como objetivo avanzar sobre su capital y recuperarla sino impedir el ingreso de los insurgentes a la Nueva Vizcaya. ${ }^{43}$ Calleja suplicaba a Salcedo que las fuerzas de las Provincias Internas auxiliaran a Zacatecas, pero poniéndose a las órdenes de los comandantes de esa provincia. Para convencerlo ponía de relieve que Zacatecas era un punto esencial de tráfico y comunicación para las Internas y por eso se esperaba que le ordenara al gobernador intendente Bonavía y demás mandos militares se subordinaran. ${ }^{44}$ Pero Salcedo

\footnotetext{
42 SÁnchez de TAGLE, Insurgencia y contrainsurgencia, pp. 96, 99, 110.

${ }^{43}$ Domínguez, "Estado, frontera", p. 223.

${ }^{44}$ AGN, OG, c. 4189, exp. 19.
} 
no estaba dispuesto a subordinar sus tropas a los comandantes del virreinato; más allá de la cuestión de la estrategia militar, el objetivo primordial era salvaguardar la jurisdicción de la insurgencia y acentuar la autonomía de la Comandancia General, dada la conflictiva relación que ya habían vivido las dos entidades. Aunque posteriormente las fuerzas de Tierra Adentro apoyaron la contrainsurgencia y avanzaron sobre Zacatecas, nunca estuvieron dispuestos a ceder el mando de sus tropas. Fueron múltiples las cartas que Calleja elevó ante el virrey y la Regencia ante la falta de respuesta de una mayor participación en la lucha contra los insurgentes de las Internas. En una carta que Salcedo remitió a Bonavía con copia a Calleja expresaba claramente que este último no entendía que "[...] las Provincias Internas no solo no pueden ocupar sus cortas fuerzas en objetos separados de su territorio $[\ldots]$ ", si no que con las que contaban les era imposible atender su propia jurisdicción. ${ }^{45}$

Sin embargo, el papel contrainsurgente de las Provincias Internas va mucho más allá de lo poco que se ha calculado. Parece que sus fuerzas se componían de tres grandes secciones que actuaban por separado según un área determinada designada con la idea de no dejar entrar a los insurgentes en la Nueva Vizcaya. Una sección comandada por José Manuel de Ochoa, dispuesta en la línea o frontera de la provincia mencionada con Coahuila; la segunda en la línea o frontera con Zacatecas bajo el mando de Allande y Larramendi, y la tercera de Melgares que actuaba más en coordinación con Ochoa. Isidro Vizcaya Canales refiere que tropas de las Provincias Internas comandadas por el capitán Pedro María

45 GonzÁlez, “Documentos de la Independencia”, pp. 55-56. 
de Allande derrotaron a los insurgentes en la acción de Riul (probablemente se refiera al actual Jiménez de Teul, Zacatecas) y con ello reconquistaron Fresnillo, además de alcanzar Allande el grado de coronel. Un español que logró escapar, posiblemente de Zacatecas, y unirse a las tropas de Tierra Adentro en Sombrerete informó que la acción se realizó el 17 de noviembre y la sección del ejército contrainsurgente estaba integrada por 300 soldados y el insurgente por 500 infantes y 180 de caballería. Agregaba que entraron a Fresnillo, parece ser que el 28 de noviembre, donde se les unió Larramendi con 300 rancheros bien armados, 50 veteranos y 150 indios flecheros, componiéndose la fuerza de un total de 1014 hombres de a caballo y 200 infantes. Asimismo, el insurgente Justo Rufino Campero le mandó una carta a Iriarte donde le decía que la avanzada se componía de 1200 hombres, entre los que había soldados veteranos, todos fusileros, indios comanches, apaches gileños y rancheros de las haciendas de las inmediaciones. El comandante militar de Zacatecas, José María Arrieta, también le comunicó a Iriarte que se le había avisado que el enemigo con fuerza respetable y de tropa veterana se hallaba en Fresnillo. ${ }^{46}$

$\mathrm{Al}$ avanzar los insurgentes de la ciudad de Zacatecas más hacia el septentrión y tomar Fresnillo, las tropas de Tierra Adentro de inmediato actuaron para frenar su avance a la Nueva Vizcaya; más que nada a eso obedecía esa movilización. Fresnillo sólo fue ocupado dos días y las tropas se replegaron de nuevo hacia Sombrerete. El 30 de noviembre fray José Antonio Iriarte decía a Rafael Iriarte que le había consolado el hecho de que el ejército que había tomado

${ }^{46}$ Vizcaya, En los albores, pp. 91, 248-249, nota 51. 
Fresnillo era sólo de 1016 hombres con tres cañones y que ya se habían regresado a Sombrerete. ${ }^{47}$ Acciones como la anterior molestaban sobremanera a Calleja, quien se quejaba de la manía de todos de defenderse cada quien en su territorio, dejando así a los insurgentes fuerzas que después nadie podría resistir.

El 14 de diciembre una sección del ejército de Tierra Adentro bajo el mando de Fernando del Castillo avanzó hacia Zacatecas. En su comunicado a las autoridades de la ciudad les dijo que el ejército de avanzada del rey de Tierra Adentro se encontraba con sus partidas volantes en las inmediaciones con el objeto de restablecer el orden y los conminaba a recibir sus tropas; si no, experimentaría los horrores de la guerra. Se le contestó que las Provincias Internas no tenían jurisdicción sobre esa capital y que entre los vasallos de Fernando lo primero que se debía cuidar era conservar los límites y defenderlos de quien pretendiera invadirlos como enemigo. Héctor Sánchez Tagle vislumbra la posibilidad de que Iriarte regresara de San Luis Potosí a Zacatecas ante la amenaza de las tropas de Tierra Adentro en lugar de acudir a ayudar a Hidalgo en la batalla de Puente de Calderón, lo que a la postre significará su fusilamiento. ${ }^{48}$

Sánchez de Tagle refiere una batalla realizada el 25 de diciembre de 1810 como una de las más importantes en el septentrión entre las fuerzas de Iriarte y las de Tierra Adentro comandadas por Ochoa, quien atacó a los insurgentes en la batalla de Fresnillo (o de Santiaguillo). No se tiene el dato exacto del número de soldados en cada bando. La batalla

\footnotetext{
47 VizcAYA, En los albores, pp. 115, 257, nota 12.

48 SáncheZ de Tagle, Insurgencia y contrainsurgencia, pp. 115-121.
} 
tuvo lugar en la hacienda de Santiaguillo, donde se sabe que estuvo presente Iriarte. El cabo Perfecto Pichardo en declaraciones dijo que las tropas de las Provincias Internas atacaron en Santiaguillo a Iriarte y se había dado una orden muy severa para que todos los vecinos de Zacatecas se presentaran en aquel punto. En un informe generado en Monterrey se decía que "Las tropas de Nueva Vizcaya por el rumbo de Durango se habían portado perfectamente derrotando en las cercanías de Teul a quinientos insurgentes y reconquistado el Fresnillo [...]" y esperaban órdenes para hacer lo mismo en Zacatecas.$^{49}$ No tenemos plena seguridad de que esta batalla sea la misma que refiere Vizcaya Canales o sean dos acciones de guerra totalmente distintas, ya que en la época se manejaba mucho el rumor y con base en eso se hacían declaraciones como verdaderas. Sea la misma acción o diferente, concordamos con Sánchez de Tagle en que la batalla de Fresnillo fue de gran importancia ya que frenó de lleno las aspiraciones de los insurgentes de entrar a las Provincias Internas de Occidente por el Camino Real de Tierra Adentro.

Pero en las Provincias Internas de Oriente la situación se presentó de forma diferente. Es importante recapitular sobre la situación jurisdiccional de ellas. Como ya dijimos, desde 1804 se ordenó la división de las Provincias Internas en dos grandes bloques, Oriente y Occidente, pero no se ejecutó la real orden. Por lo tanto, Coahuila y Texas siguieron bajo el mando del comandante general Salcedo; por su parte el Nuevo Reino de León y Nuevo Santander estaban en una situación ambigua entre éste y el virreinato. De las de Occidente Salcedo continuó con el plan de que no entraran

49 Sánchez de TAgLe, Insurgencia y contrainsurgencia, pp. 112-120. 
a la jurisdicción los insurgentes y a eso obedecía su estrategia militar y enconado conflicto con el virreinato. Calleja le suplicaba a Salcedo que enviara tropas a liberar San Luis Potosí, a lo que el comandante general accedió en parte. Las fuerzas de Coahuila se concentraron en el campamento de Aguanueva bajo el mando del gobernador de la provincia, el coronel Antonio Cordero. Salcedo, en su estrategia militar ya mencionada, decidió que la base militar de Coahuila no debía abandonarse y solo envió una expedición bajo el mando del capitán Mariano Varela. Se compondría de 1000 hombres: 500 de Coahuila, 250 del Nuevo Reino de León, que ya estaban en Aguanueva, a los cuales se incorporaría otro tanto de Nuevo Santander. Los últimos, debido a los problemas de remonta, nunca llegaron y entre deserciones y enfermos solo se completaron 700 hombres. Cordero se quedó en Aguanueva con otros 700 y cuatro cañones. ${ }^{50}$ Por su parte Mariano Jiménez, que había recibido la encomienda de revolucionar en las Provincias Internas de Occidente, marchó de San Luis Potosí al norte y pronto juntó un ejército de 8000 hombres y 16 cañones.

El 7 de enero de 1811 Jiménez llegó a Aguanueva pero no hubo batalla ya que ante las primeras maniobras de los insurgentes las tropas de Cordero se pasaron a éstos. El gobernador huyó pero bochornosamente fue perseguido y capturado por sus mismas tropas. De allí todo fue gloria para Jiménez, quien entró a Saltillo el 8 de enero y a Monterrey el 26. Pero pronto todo cambiaría, la derrota de Miguel Hidalgo en Puente de Calderón el 17 de enero y también la entrada de tropas de las Provincias Internas a Parras, comandadas

50 Vizcaya, En los albores, p. 113. 
por Facundo Melgares, determinaron a Jiménez a reconcentrar sus tropas. La última noticia era la más grave por estar amenazado Saltillo, punto vital para el dominio de las Provincias Internas de Oriente. Jiménez salió a combatir a Melgares pero solo se dio una escaramuza en Patos entre las avanzadas de los dos ejércitos y cada una se atribuía la victoria. ${ }^{51}$

Después de la derrota de Puente de Calderón, Hidalgo y los demás insurgentes, en su marcha al septentrión, entraron a Zacatecas para dejarla el 4 de febrero de 1811. Las tropas de Tierra Adentro, comandadas por Ochoa, se aproximaron a la ciudad con 600 hombres de caballería y 300 indios flecheros. Ochoa informó que envió a José Francisco Álvarez con tres compañías de su división, dos de caballería y una de tarahumaras, y a fuerza viva hubo de rendirse Zacatecas. Desde entonces las fuerzas de Tierra Adentro permanecerían por largo tiempo allí y Ochoa fue nombrado intendente. ${ }^{52}$ Tal designación posiblemente tenga que ver con una estrategia del virrey y de Calleja para que las tropas norteñas no abandonaran la ciudad o se replegaran siguiendo la máxima de Salcedo de solo evitar la entrada de insurgentes a la Nueva Vizcaya.

Cuando Hidalgo estuvo en Guadalajara comisionó a José María González Hermosillo para atacar las Provincias Internas de Occidente por Sinaloa y Sonora. En el Real del Rosario, Hermosillo venció al coronel Pedro Villa Escusa. Allí reunió una fuerza de 4225 infantes, 476 de caballería, armados con 6 cañones, 900 fusiles, algunas escopetas y carabinas, 200 pares de pistolas y gran cantidad de lanzas.

51 Vizcaya, En los albores, pp. 117-118, 129, 154.

52 SÁnchez de TAgle, Insurgencia y contrainsurgencia, pp. 140-144. 
En San Ignacio Piaxtla, el 8 de enero de 1811, se enfrentó con las fuerzas de las Provincias Internas de Occidente, comandadas por el gobernador intendente de Sonora-Sinaloa, Alejo García Conde. No se tienen datos del número de fuerzas que traía, pero se sabe que lo acompañaba un grupo considerable de indios ópatas armados con fusiles y lanzas. ${ }^{53}$ Mientras Bustamante refiere que Hermosillo prácticamente cayó en una emboscada, García Conde informa que, habiendo entrado a Sinaloa los insurgentes, a costa de indecibles trabajos formó un proporcionado ejército. Recorrió a marchas forzadas desde Arizpe, la capital de la intendencia, 100 leguas hasta San Ignacio para batir a los insurgentes, quienes contaban con 8000 efectivos. Destacó que él mismo dirigió las acciones causando la muerte a 750 y los restantes insurgentes huyeron del campo de batalla abandonando la artillería, equipaje y demás material bélico que traían. En su precipitada retirada habían dejado libres los partidos que habían conquistado: Piastla, Copala, Maloya, Mazatlán y Rosario. ${ }^{54}$ García Conde, que buscaba un puesto más alto que de intendente, realzó sobre manera sus acciones en su informe. El virrey Francisco Venegas y el comandante de la Nueva Galicia, José de la Cruz, le mandaron calurosas felicitaciones. El segundo le decía:

Si asegurado vuestra señoría de todos los pueblos que deja por su espalda creyese conbeniente hazer una expedición sobre Acaponeta o qualquier otro paraje considero que sería utilísimo [...] Puede vuestra señoría penetrar con su exercito por toda esta provincia si lo encontrare útil y en ella encontrará vuestra

${ }^{53}$ Bustamante, Cuadro histórico, pp. 176-181.

${ }^{54}$ AGN, PI, 207, ff. 317-318. 
señoría y sus tropas todo quantos auxilios sean posibles. Tiene vuestra señoría con todo el lleno de autoridad el mando de los puntos que ocupe y sus inmediaciones para hazer escalaciones de justicia sin consultarme, pues las actuales circunstancias exijen imperiosamente que no reparemos de la rutina miserable que todo lo entorpeze y retarda. No se moleste vuestra señoría tampoco en dar parte a esta Real Audiencia, pues estando ambos en comunicación nos participaremos recíprocamente quanto haya ocurrido y ocurra en nuestros exercitos respectibos. Castigue vuestra señoría hasta con el último suplicio los traidores que ha aprisionado, sean o no de este distrito [...]

He de merecer a vuestra señoría que en todo este Reino de Nueva Galicia disponga a su arbitrio, ya para dar órdenes, hazer arrestos, ahorcar y tomar todas quantas medidas considere de nezesidad para el vien del servicio sin consultarme ni tener el menor reparo, representa vuestra señoría mi misma persona en todas partes... y puede disponer de la autoridad en todas ocasiones como la halle más necesario $\left[\ldots .{ }^{55}\right.$

Es importante señalar que era una invitación, no una orden, ya que De la Cruz no tenía jurisdicción sobre las Internas; por lo que sabemos, García Conde no avanzó hacia Acaponeta. La victoria era por demás importante para las Provincias Internas ya que Salcedo no tendría que navegar con otro frente de batalla y Nueva Vizcaya no se vería asediada por los insurgentes en oriente y occidente a manera de pinzas.

El 21 de marzo Hidalgo y demás insurgentes fueron capturados en Acatita de Baján cambiando todo el panorama del movimiento. En solo tres meses las Provincias Internas

${ }^{55}$ AGN, $P I, 207$, ff. 319-319v. 
de Oriente habían pasado a la insurgencia y regresado a la contrainsurgencia, habiéndose dado solo la batalla del Puerto de Piñones. El 12 de marzo Ochoa partió hacia Coahuila en persecución de los insurgentes y después de la captura de Hidalgo estaba en Parras. En Monclova había contrarrevolucionarios y Calleja se hallaba en San Luis Potosí, por lo que la posición de Ignacio López Rayón, que se encontraba en Saltillo, se volvió muy riesgosa y por esa razón decidió regresar al sur. El 1ํo de abril el ejército de Tierra Adentro, comandado por Ochoa y el de López Rayón trabaron combate en el Puerto de Piñones o el Carnero. Los insurgentes contaban con alrededor de 3500 hombres y más de 20 cañones, mientras las fuerzas de Nueva Vizcaya eran de poco más de 800 . La batalla duró seis horas y aunque Ochoa logró capturar 240 prisioneros y 2 cañones, Rayón siguió con su marcha a Zacatecas sin ser perseguido. ${ }^{56} \mathrm{Aca}-$ baba así la insurgencia en las Provincias Internas de Oriente y en Occidente no había podido penetrar, pero el ejército de Tierra Adentro continuaría activo por más tiempo.

Mas la prisión de los principales insurgentes en Baján no va a ser el parteaguas de más cooperación y concordancia entre las Provincias Internas y el virreinato. Las desavenencias de Calleja con Salcedo y Bonavía se van a acumular y acentuar. Salcedo ordenó el traslado de Hidalgo y demás jefes a Chihuahua, y le comunicó al gobernador contrainsurgente provisional de Coahuila Simón de Herrera: “[...] he determinado que en los términos que ya expresaré sean conducidos a esta villa [Chihuahua] el cura Ydalgo, Allende

56 Vizcaya, En los albores, pp. 183, 193. 
(si se hubiera aprendido) Aldama, Abasolo, Yriarte", ${ }^{57}$ para ser juzgados y allí serán fusilados. Calleja quería que fueran conducidos a la Ciudad de México pero el virrey Venegas, sin poder ni jurisdicción sobre las Provincias Internas nada pudo hacer. En ningún momento Salcedo hubiera permitido que se le escapara tal oportunidad de gloria. Fueron apresados en su jurisdicción y por tropas de su mando, así que ni Venegas ni Calleja podían influir en su determinación. Poco después Salcedo obtendrá su recompensa al ser nombrado por la Regencia mariscal de campo. ${ }^{58}$

Lo anterior no hacía más que agregar a Calleja más encono contra los comandantes de las Provincias Internas. El que Ochoa no persiguiera a López Rayón y García Conde no respondiera como José de la Cruz deseaba acentuaba el conflicto. Calleja pedía a Salcedo que el ejército de Tierra Adentro no se retirara y siguiera resguardando Zacatecas, pero también que avanzara y atacara a los insurgentes que habían vuelto a levantarse en Tlaltenango y Colotlán. Calleja repetidamente los acusó ante el virrey diciéndole que no hacían caso a sus instrucciones militares, que no contestaban sus oficios y le pidió que los responsabilizara de las malas consecuencias que se pudieran presentar. Directamente acusó a Bonavía del fracaso de algunas campañas militares en Zacatecas y la región de Colotlán. ${ }^{59} \mathrm{El}$ problema continuó y los comandantes de las Internas cuando tenían acciones de armas y derrotaban a los insurgentes no los perseguían. El 11 de septiembre de 1811 Calleja le reclamaba a Bonavía:

\footnotetext{
57 AGN, OG, 204, exp. 60, ff. 88-90v.

58 Véase Domínguez, "Estado, frontera”, pp. 233-234.

59 González, “Documentos de la Independencia”, pp. 55-56.
} 
[...] el Comandante e Yntendente ynterino de Zacatecas me avisa con fecha de este mes que el Teniente Coronel Don José López después de la acción del Campo de San Francisco trata de abandonar la importante posición entre aquella Ciudad y Aguas Calientes y la persecución que convenía executara contra las reliquias de dicha gavilla, cuyos caudillos [se] fugaron todos $[\ldots]$

No pueden ocultar a V. S. los males que esta arbitrariedad y falta de sugeción a los planes y disposiciones militares ocasiona al buen éxito de ellas. Hasta ahora han podido ser de menos consecuencias por la inmediación de este exercito y por la de una División al cargo de Señor coronel Don Diego García Conde a cuya proximidad huyeron los rebeldes que batió López $[\ldots] .^{60}$

Agregaba que Ochoa le informó que le ordenaron suspender sus operaciones por el cañón de Tlaltenago y retirarse a Durango con el argumento de que no había en la región tropas del virreinato que lo apoyaran. Calleja aseveraba que las había de Guadalajara cuando las circunstancias lo habían permitido. Decía que era indispensable que las tropas de Tierra Adentro permanecieran en Zacatecas o en el lugar que lo considerara más apropiado el comandante militar de esa provincia por el peligro de que los insurgentes se apoderaran de nuevo de ella debido a sus pocas y débiles fuerzas. De ser así otra vez quedarían obstruidas las comunicaciones y las diligencias que desde México iban a las Provincias Internas con efectos del rey y particulares no podrían pasar, quedando además expuesto Durango, agregaba Calleja. También señalaba que en breve debía trasladarse a Valladolid

${ }^{60}$ AGN, OG, c. 4096, exp. 19. 
para destruir las grandes reuniones de insurgentes que allí estaban reunidas, para lo cual debía agregársele la división de Diego García Conde desde Aguascalientes.

Las atenciones del Virreinato no han permitido embiar a Zacatecas una fuerza capaz de resguardarla suficientemente; se necesita otra campaña para disipar los grandes cuerpos de enemigos que se han formado y fortificado por la parte sur de este Reino y para restablecer el sistema militar que debe ponerlo en completa seguridad protegiendo todas las Provincias y es necesario el auxilio de tropas de esas Provincias con órdenes a sus comandantes para que procedan en todo lo relativo al servicio de Armas con sugeción a las órdenes y planes de los gefes del Distrito en que se hallan, por ser así conforme lo que el Rey tiene declarado en sus ordenanzas y a lo que exige el buen orden y la unidad tan necesaria en las operaciones militares. ${ }^{61}$

No conforme con escribir a Bonavía se dirigió al comandante general Salcedo manifestándole su amargura de que cuando más pensaba que por el efecto de tantas victorias había llegado a su término la sublevación, se veía comprometido en otra campaña sobre Valladolid. Tenía noticias de que los insurgentes se habían apoderado de Pátzcuaro y Zitácuaro, pero le pesaba más la derrota del teniente coronel Antonio Fuentes a manos de Morelos en Tixtla e inmediaciones de Acapulco, ya que así habían quedado expuestas las provincias de Puebla y Oaxaca. Reconoció ante Salcedo que las fuerzas de Tierra Adentro contribuían a la tranquilidad y pacificación de Zacatecas, las expediciones que se habían realizado al cañón de Tlaltenango y la derrota que infringió

${ }^{61}$ AGN, OG, c. 4096, exp. 19. 
López a los insurgentes que se habían apoderado de Aguascalientes. Por todo lo anterior, le suplicaba a Salcedo que sus tropas continuaran en Zacatecas. Agregaba que los teniente coroneles López y Ochoa para todo esperaban las órdenes de Bonavía, lo que provocaba que sus movimientos se dieran con lentitud y retraso, lo cual era muy inconveniente en las circunstancias que se vivían y trastornaba todos sus planes.

Calleja le pidió a Bonavía que mientras las tropas de las Provincias Internas estuvieran en Zacatecas ordenara a sus comandantes "[...] que estén enteramente a mis órdenes para todas las acciones y servicio de armas [...].” Pero además le pidió que sustituyera a López por otro oficial de más actividad ya que al ordenársele a Ochoa retirarse a Durango debía entregarle a López el mando de su división, el cual no reconocía más órdenes que las de Bonavía y que en espera de ellas siempre vacilaba en lo que debía ejecutar. Acusó a López de que se preparaba para retirarse de las inmediaciones de Aguascalientes, donde era absolutamente necesario para acabar de destruir los restos del cuerpo de insurgentes que el mismo López había derrotado. Calleja quería tocar las fibras sensibles de Salcedo, por eso siempre mencionaba las probabilidades de que el propio Durango pudiera verse en peligro e interrumpida la comunicación, y prácticamente lo amenazaba diciendo que necesitaba su respuesta inmediata para no suspender los carruajes y transportes que desde la Ciudad de México se dirigían a las Provincias Internas para evitar que cayeran en manos del enemigo. ${ }^{62}$

El 18 de septiembre de 1811 Bonavía le contestó a Calleja que las órdenes que le había girado a López eran conforme

${ }^{62}$ AGN, OG, c. 4096, exp. 19. 
a las de Salcedo y se referían a que el teniente coronel debía tener las tropas situadas de forma que auxiliara a Zacatecas y resguardara las principales entradas a la Nueva Vizcaya. Sobre López dijo que, cumpliendo con ambos propósitos y sin habérsele reunido la corta división de Ochoa, mandó un destacamento a recorrer los pueblos del cañón de Tlaltenango, y con las disminuidas tropas que le quedaron marchó a recuperar Aguascalientes, de la cual se habían apoderado los insurgentes. Resaltaba la buena disposición del militar agregando que había pasado poco tiempo de lo anterior cuando López recibió un oficio de su subordinado que guiaba el destacamento que mandó al cañón de Tlaltenango exponiéndole lo conveniente que era acabar de pacificar los pueblos que visitó, librarlos de las gavillas de insurgentes, y aprehender y castigar a los cabecillas como ya lo había hecho con algunos. Los planes fueron autorizados por López y enseguida marchó a Jerez a recibir la división de Ochoa.

Bonavía decía que aunque tuviera facultades para poner a disposición del intendente de Zacatecas un cuerpo de tropas, no sería de una fuerza capaz de tantas atenciones como se exigía de las tropas ya destacadas en esa provincia. Al contrario, se quejó de que Sombrerete desde hacía mucho tiempo debía estar resguardado por su mismo vecindario ya que demasiada falta le hacían las tropas que allí tenía emplazadas. Asimismo que Zacatecas debía ya defender el partido del Mezquital, que se había sublevado al ser invadido por los pueblos alzados de Nayarit encabezados por misioneros y cortando la comunicación con Tepic. Debido a lo anterior Bonavía pensaba que el comandante de Nueva Galicia, José de la Cruz, podía contribuir a auxiliar las operaciones de las fuerzas de Tierra Adentro sobre el Mezquital. Por otra 
parte, el intendente interino le mandó un plan a Bonavía donde le indicó cómo colocar las tropas de Provincias Internas, a lo cual le contestó que consultaría a López y motivó las quejas del funcionario ante Calleja. ${ }^{63}$

En julio de 1812 el Consejo de Regencia ordenó que se hiciera efectiva la división de las Provincias Internas en Occidente y Oriente, cada una con su comandante general y dependientes del virreinato. ${ }^{64}$ El 19 de febrero de 1813 Bernardo Bonavía fue nombrado comandante general de Occidente ${ }^{65}$ y el 4 de marzo de ese mismo año Calleja virrey. Pero lejos de limarse asperezas entre los dos personajes cada vez se agudizaban más. ${ }^{66}$ Calleja, ahora desde una posición de poder, va a extraer y exprimir humana y materialmente a las Provincias Internas de Occidente, en especial la Nueva Vizcaya, en apoyo a la contrainsurgencia. Existía la visión en Calleja de que por no haberse desarrollado la guerra en ellas se contaba con abundancia. Ante una solicitud de Bonavía de numerario, el virrey Calleja le respondía que bajara los gastos a lo indispensable disminuyendo el crecido número de tropas que tenía "[...] sobre las armas en esas Provincias abundantes y pacíficas [...]". ${ }^{67}$

Ahora las tropas de Tierra Adentro no solo van a cuidar Zacatecas, Calleja también las utilizará para reguardar San

63 AGN, OG, c. 4096, exp. 19.

64 AGN, PI, 129, ff. 1-18v., Providencias tomadas por los excelentísimos Sres. Virrey D. Francisco Xavier Venegas y D. Félix María Calleja en cumplimiento de reales órdenes de $1^{\circ}$ de mayo de 1811 y 24 de julio de 1812 para llevar a efecto la división de las Provincias Ynternas de este Reyno (1812).

65 AGN, PI, 129, ff. 19-22v.

${ }^{66}$ Véase Domínguez, "Estado, frontera”, cap. IV.

67 AGN, PI, 129, ff. 61-67v. 
Luis Potosí. ${ }^{68}$ Bonavía se quejaba de la exigencia hacia las Provincias Internas de Occidente diciendo que además de lo anterior le había proporcionado al comandante general de Oriente 400 hombres; tenía 200 acantonados en Coahuila, con la tarea de perseguir a los insurgentes que entraron en Monterrey, sacados de las compañías volantes y presidios. Además, había tenido que juntar tropas de Nueva Vizcaya y Sonora para mandarlas a Nuevo México, que estaba amenazado por estadounidenses posiblemente aliados con apaches. Tenía una división, compuesta, sobre todo, por tropas de los presidios de Sonora, en el Rosario en guerra viva con los insurgentes. El resultado era que los presidios quedaban guarnecidos solo por vecinos armados y las poblaciones a merced de los indios hostiles y los considerados de paz en cualquier momento podían sublevarse. ${ }^{69}$

Pero Calleja no solo obtenía soldados de las Provincias Internas de Occidente, la extracción que de ellas empezó a hacer iba más allá de la aportación de hombres. Bonavía decía que su gobierno había vestido y montado a las tropas de Calleja, además de ayudarlo con donativos, remontas y escopetas salidas de la fábrica de armas de chispa de Chihuahua. ${ }^{70} \mathrm{El}$ mismo Calleja decía que los fieles habitantes de las Provincias Internas habían donado 1813 caballos, pero ellas no habían sufrido la devastación de la guerra contra los insurgentes. ${ }^{71}$ Enterado Calleja de la existencia de la fábrica de armas de Chihuahua y que de ella se había remitido material bélico a las provincias de Nueva Galicia

\footnotetext{
68 AGN, PI, 129, f. 35.

69 AGN, PI, 129, ff. 14-17.

70 AGN, $P I, 129$, ff. 51-54.

71 AGN, PI, 129, ff. 61-67v.
} 
y Zacatecas, pronto pidió que se enviaran, en agosto de 1813, 100 carabinas al Regimiento de Moncada en San Luis Potosí.

Ante la escasez de armamento en las Provincias Internas y no poder conseguirlo en España, la fábrica fue establecida por Salcedo a mediados de 1808. Nombró maestro mayor a Martín Irigoyen, armero de la Compañía de San Carlos de Cerrogordo, funcionando sin tener que tomarse caudal alguno de la Real Hacienda. Para su establecimiento, acopio de materiales, herramientas y pago de empleados se tomó de los fondos de las compañías veteranas de Nueva Vizcaya con la condición de reintegrarlos. En 1809, con donativos de las personas más pudientes de la provincia, se estableció un fondo por un total de 17009 pesos. Con el valor de las escopetas fabricadas y en efectivo se reembolsó a las compañías veteranas lo prestado, quedando todavía 15196 pesos. $^{72}$ En un inicio la fábrica podía entregar hasta 50 escopetas al mes. En 1809 Salcedo le envió al virrey una escopeta producida en Chihuahua y le sugirió que se establecieran otras fábricas en la Nueva España en lugares donde los materiales y la mano de obra fueran más baratos, ya que en Chihuahua los costos de producción eran de hasta 30 pesos por escopeta. ${ }^{73} \mathrm{Al}$ estallar la insurgencia en el virreinato se seleccionó un grupo de trabajadores para que auxiliaran a Irigoyen en sus faenas. Se fabricaron espadas, cuchillos, machetes y lanzas, se recompusieron armas de fuego y se fundieron los primeros cañones. Así se mejoró la dotación de soldados

72 AGN, IV, c. 3603, exp. 036.

73 Vizcaya, En los albores, pp. 139, 266, nota 41. 
permanentes y milicianos y se pudo armar a los sirvientes de ranchos y haciendas. ${ }^{74}$

Para 1813 el precio de la escopeta no había variado; el administrador de la fábrica, Diego de Aguirre, refería que el costo de producción de una de ellas era igual al de 1809. Puesto que en la provincia siempre podían suscitarse ataques de los indios se debía andar armado, por lo que la demanda era constante. A los particulares se les vendía la escopeta a 30 pesos y a los soldados veteranos y milicianos a 20. Desde la fundación de la fábrica hasta fines de mayo de 1813 el total de armas manufacturadas fue de 2256 escopetas, más 80 fusiles con bayoneta que el ayuntamiento de Sombrerete encargó, además de 323 que el intendente de Zacatecas había pedido, en los dos casos para las milicias. Para 1813 la fábrica podía construir y entregar 100 escopetas por mes o igual número de fusiles de gran calidad. ${ }^{75} \mathrm{En}$ cuanto a la exigencia de Calleja de armamento de la fábrica Bonavía le informó que con las armas producidas en Chihuahua se había provisto en gran medida a las guarniciones de la Nueva Vizcaya. Incluso a las milicias del Nuevo Reino de León, Nuevo Santander, Texas y a las tropas alistadas con motivo de la insurrección, pero aun así faltaba armamento en las Provincias Internas y por eso también se había intentado comprarlo fuera de ellas. ${ }^{76}$ Durante la guerra en el virreinato Querétaro se convirtió en el principal proveedor de uniformes y utensilios para los contrainsurgentes. ${ }^{77}$

\footnotetext{
${ }^{74}$ Almada, El periodo de la Independencia, p. 10.

75 Vizcaya, En los albores, pp. 139, 266, nota 41.

76 AGN, IV, c. 3603, exp. 036.

77 OrTIZ, Guerra y gobierno, p. 45.
} 
La batalla que libraban las Provincias Internas con el virreinato va más allá de la cooperación y actitud en el combate a los insurgentes, tiene que ver más con la lucha contra la sujeción que quería establecer el virreinato a las provincias norteñas y en su contraparte con sus posturas autonómicas. En medio de las circunstancias de la insurgencia y con la interrupción del envío de moneda de la Ciudad de México a las Provincias Internas, Salcedo mandó crear tres casas de moneda en Sombrerete, Chihuahua y Durango respectivamente, ${ }^{78}$ haciendo de esta manera y en esas circunstancias realidad el anhelo de la casa de moneda septentrional a la que fuertemente se opuso el virreinato. Al acentuarse el conflicto entre las dos jurisdicciones los virreyes más que nunca buscaron socavar esa autonomía elevando quejas a la corona y consiguiendo al fin la subordinación militar de la Comandancia General. A disposición del virreinato, los recursos militares y materiales de las Provincias Internas van a ser utilizados para combatir la insurgencia no sin antes debilitarlas. Ya proclamada la independencia en el virreinato las fuerzas de Pedro Celestino Negrete tomarán Durango y la Villa de Chihuahua para proclamar en ellas la independencia.

\section{IV}

Los diputados de las Provincias Internas de Oriente y Occidente hicieron grandes esfuerzos por evitar la fragmentación y que los estados fueran unidades territoriales más grandes que las actuales demarcaciones norteñas. En Oriente,

78 Almada, El periodo de la Independencia, pp. 74-76. 
Saltillo, bajo el liderazgo del diputado Miguel Ramos Arizpe, se convirtió en el principal propulsor de la jurisdicción para que sus cuatro provincias siguieran conformando una unidad territorial político administrativa. ${ }^{79}$ En Occidente los diputados por la parte septentrional de Nueva Vizcaya, liderada por el ayuntamiento de Chihuahua y apoyada por Nuevo México, hacían lo mismo. Pero las oligarquías autonómicas locales sostuvieron enconados conflictos por convertir sus centros urbanos en capitales y asiento de los poderes estatales; la situación se presentó en todas la Provincias Internas: en Oriente los comerciantes agricultores terratenientes de Saltillo, de la provincia de Coahuila, contra los agricultores militares de Monterrey, de la Provincia de Nuevo León, se enfrascaron en una ruda pelea por ser la sede de los poderes. ${ }^{80}$ Tamaulipas ya se había separado de esta última y pronto sus principales centros urbanos, San Carlos y Aguayo, iniciaron la batalla por convertirse en la capital. ${ }^{81}$

En lo que había sido la provincia de Sonora-Sinaloa y después intendencia de Arizpe la disputa inicial se dio entre las poblaciones de Arizpe contra Ures y Pitic. Posteriormente hubo gran inconformidad, cuando al crearse el Estado Interno de Occidente, por decreto del Congreso Nacional Constituyente, se fijó al Fuerte, enclavado en la región de Sinaloa, como sede de los poderes estatales. Aunado a lo anterior se señaló que Sinaloa por su mayor población debía

79 Jáuregui, “Nuevo León”, pp. 356, 359, 365-366. También Sheridan, "El primer federalismo".

80 Jáuregui, “Nuevo León”, p. 360.

81 Herrera, “Autonomía y decisión”, pp. 432, 437. 
tener seis diputados y Sonora solo cinco, lo cual representaba un duro golpe para la oligarquía de Arizpe. ${ }^{82}$

En un inicio los diputados de Occidente planteaban la unidad de las cinco provincias: Durango, Chihuahua, Sonora, Sinaloa y Nuevo México formando una sola entidad territorial política administrativa. En cuanto a la organización política nacional, en Chihuahua con mucha cautela se mostraba la inclinación por el establecimiento de una federación. ${ }^{83}$ Ya separadas Sonora y Sinaloa, Chihuahua luchaba para crear una sola entidad junto con las provincias de Nuevo México y Durango, pero nunca se abandonaba la exigencia de que la ciudad de Chihuahua fuera la capital y sede de las autoridades. ${ }^{84} \mathrm{Al}$ crearse el Estado Interno del Norte con las tres provincias anteriores se señaló a Chihuahua como capital, situación que no estuvo dispuesto a aceptar Durango. Las poderosas oligarquías de las dos ciudades determinaron la fragmentación para crear los actuales estados de Chihuahua y Durango. ${ }^{85}$

No hay duda que la aportación de las Provincias Internas a la derrota de los insurgentes fue determinante, pero con un costo humano y material muy alto. Al supeditarse en 1813 la comandancia general al virreinato se utilizaron sus fuerzas militares y materiales para contener y luego sofocar la insurgencia, lo cual las desgastó y debilitó, y como consecuencia el autonomismo del conjunto territorial o multiprovincial perdía fuerza para aglutinar a las oligarquías autonómicas regionales dando paso a los autonomismos locales. Así prevaleció

82 Hernández, “Las provincias”, pp. 561, 577-578.

${ }^{83} \mathrm{AHMCH}, \mathrm{CG}$, c. 54, exp. 24.

${ }^{84}$ Altamirano y Villa, Chibuahua, pp. 226-259.

${ }^{85}$ Domínguez, "Estado, frontera", pp. 353-355. 
el posicionamiento autonómico localista de los ayuntamientos más poderos, por lo que el proyecto de unidad multiprovincial perdió fuerza y por lo tanto toda tendencia separatista. Chihuahua y otras muchas provincias con tradición autonomista prefirieron o se vieron forzadas a unirse a lo que fue el virreinato de la Nueva España para constituir una sola nación en lugar de conformar naciones independientes.

Al perder fuerza el proyecto autonomista multiprovincial, nada evitó que el factor que alimentaba las autonomías locales se desatara, factor muy pragmático: las distancias. En las Provincias Internas la separación entre pueblos y de éstos con los centros de administración política y económica era enorme. Los traslados para los trámites burocráticos y eclesiásticos eran muy largos y por lo tanto muy costosos. Dar seguimiento a problemas o pleitos judiciales en las reales audiencias de la Ciudad de México o Guadalajara implicaba viajes que podían durar semanas. El tiempo, la distancia y el costo lo hacían muy difícil y complicado. Cuando se establece el sistema electoral gaditano cada nivel de elección: partido, provincial e ir a la sede de la diputación provincial, implicaba, en la mayoría de los casos, recorrer una mayor distancia, no se diga tener que ir hasta Cádiz. Cuando la Villa de Chihuahua pelea con Durango por ser la sede de los poderes es apoyada por las provincias de Sonora y Nuevo México, ya que un traslado desde Arizpe o Santa Fe hasta Durango era mucho más largo y costoso que ir a Chihuahua. Muy ilustrativo es el caso del diputado de la que probablemente fue una de las provincias más lejanas a la metrópoli del imperio español: Nuevo México. Su diputado a Cortes, Pedro Bautista Pino, llegó a 
Cádiz en agosto de 1812, cuando ya la Constitución había sido publicada. ${ }^{86}$

Los ayuntamientos de Paso del Norte, Socorro y San Lorenzo formaban parte de la provincia de Nuevo México pero en 1823 solicitaron al Congreso nacional que se les considerara parte de la provincia de Chihuahua que se segregaría de Durango. La razón de más peso que dieron tenía que ver con aquello que siempre esgrimía Chihuahua contra Durango para establecer las instituciones de gobierno: las distancias. Explicaron que entre Paso del Norte y Santa Fe, la capital de Nuevo México, la distancia era de alrededor de 150 leguas $(628 \mathrm{~km})$ y a Chihuahua solo de 90 $(377 \mathrm{~km})$. Así que para ir y volver de Santa Fe había que viajar 300 leguas desiertas e infestadas de enemigos navajos. ${ }^{87}$ Aunque esos ayuntamientos tenían más lazos económicos, político y culturales con Chihuahua, a final de cuentas el pragmatismo relativo a la distancia imperaba. Ser diputado implicaba dejar familia, negocios u ocupaciones por largas temporadas, un alto precio que pocos estaban dispuestos a pagar. Así que en el septentrión la distancia no era un simple factor sino un aspecto determinante para los habitantes de cada pueblo y ciudad a la hora de gestionar y pelear equipamiento gubernamental e institucional. La exigencia de más diputaciones provinciales en el septentrión va también directamente relacionada a esos aspectos geoespaciales.

Ya vimos el clamor de la sociedad en general y autoridades por el establecimiento de una real audiencia en el septentrión no solo por la lejanía de la de México o de Guadalajara,

86 Weber, La frontera norte, p. 48.
87 Orozco, El estado, pp. 131-132. 
y no solo como elementos de impartición de justicia sino también de ejercicio de gobierno. Aunque parezca inverosímil en un régimen volcado a lo militar que implicaba la Comandancia General, los mismos militares gestionaban la real audiencia como un factor necesario de gobierno.

Las reincidencias de las rebeliones de los indios supuestamente asimilados al sistema colonial y la falta de proceso judicial y sentencia a los que se atrapaba y se dejaba ir por la ausencia de instancias judiciales y órganos de gobierno pesaba en la sociedad septentrional. También la falta de equipamiento gubernamental había hecho que los pueblos septentrionales vieran en las instituciones de gobierno algo fundamental y necesario para el orden y organización social. Las instituciones de gobierno eran pocas en el septentrión, los ayuntamientos eran muy escasos, así que ante la posibilidad de contar con instituciones gubernativas que abría la Constitución de Cádiz, ya fuera diputaciones provinciales o ayuntamientos, definitivamente no era algo que se iba a dejar pasar y los pueblos septentrionales donde estaban asentadas las principales oligarquías iban a demandar ser sede de poderes gubernamentales. Por último, otro aspecto es que esas oligarquías querían copar las nuevas áreas de poder que se estaban creando para no ser desplazadas. Pugnaban por que sus ciudades fuesen el asiento de los poderes estatales; por esos factores el autonomismo localista prevaleció y determinó la fragmentación de esas grandes unidades territoriales, para luego sumarse al pacto interoligárquico nacional.

En las Provincias Internas la federación no tiene su antecedente en las intendencias. Tampoco son las diputaciones provinciales el factor esencial político del origen del 
federalismo norteño, únicamente son el medio que las oligarquías utilizan para expresar sus posturas autonómicas. En el caso de Chihuahua es más claro: no tuvo diputación provincial en 1813, no fue sede de intendencia. En todo caso, para este estado su antecedente político más cercano sería el distrito electoral, conformado para las elecciones a Cortes y diputaciones provinciales, que se constituyó con el territorio de la parte norte de la Nueva Vizcaya, pero también era parte del mismo la provincia de Nuevo México. Cuando Chihuahua fue capital de las Provincias Internas, logró funcionar como tal y con ello adquirió fuerza y poder, pero al supeditarse al virreinato la comandancia general, aunado a que al nombrarse a Bonavía sucesor de Salcedo en 1813 siguió residiendo en la ciudad de Durango, provocó que Chihuahua perdiera poder. Por lo tanto su proyecto de unidad de las Provincias Internas de Occidente también. Pero su poderosa oligarquía, anclada en el ayuntamiento, tenía la fuerza suficiente para con su territorio de influencia suscribir el pacto interoligárquico y conformar un estado de la federación.

\section{SIGLAS Y REFERENCIAS}

AGN, OG Archivo General de la Nación, ramo Operaciones de Guerra, Ciudad de México.

AGN, PI Archivo General de la Nación, ramo Provincias Internas, Ciudad de México.

AGN, RC Archivo General de la Nación, ramo Reales Cédulas, Ciudad de México.

AGN, IV Archivo General de la Nación, ramo Indiferente Virreinal, Ciudad de México.

AHMCH, CG Archivo Histórico Municipal de Chihuahua, fondo Colonial, sección Gobierno, Chihuahua, Chihuahua. 
AHMJ, CGPR Archivo Histórico Municipal de Jiménez, fondo Colonia, sección Guerra, subsección Presidios y milicia, serie Reglamentos, Jiménez, Chihuahua.

Almada, Francisco R.

Resumen de historia del estado de Chibuabua, México, Libros de México, 1955.

El periodo de la Independencia en Chibuabua, Chihuahua, Universidad de Chihuahua, 1965.

Altamirano, Graziella y Guadalupe Villa

Chibuabua, textos de su historia: 1824-192, Chihuahua, Universidad Autónoma de Ciudad Juárez, Gobierno del estado de Chihuahua, Instituto de Investigaciones Dr. José María Luis Mora, 1988.

Annino, Antonio

"El pacto y la norma. Los orígenes de la legalidad oligárquica en México", en Historias, 5 (1984), pp. 3-31.

Ávila, Alfredo y Virginia Guedea (coords.)

La independencia de México: temas e interpretaciones recientes, México, Universidad Nacional Autónoma de México, 2010.

Bancroft, Hubert Howe

History of the North Mexican States, San Francisco, Bancroft Company Publishers, 1884, vol. xv.

Benson, Nettie Lee

La diputación provincial y el federalismo mexicano, México, El Colegio de México, Universidad Nacional Autónoma de México, 1994.

Bustamante, Carlos María

Cuadro histórico de la Revolución mexicana, México, Fondo de Cultura Económica, 1985. 
Cavazos Garza, Israel

Breve historia de Nuevo León, México, Fondo de Cultura Económica, El Colegio de México, Fideicomiso Historia de las Américas, 1994.

Ceballos, Manuel (comp.)

Encuentro en la frontera, México, El Colegio de México, 2001.

Cutter, Charles R.

"La Real Audiencia del norte de la Nueva España: historia de un proyecto frustrado", en Memoria del X Congreso del Instituto Internacional de Historia del Derecho Indiano, México, Universidad Nacional Autónoma de México, 1995, pp. 277-292.

Domínguez Rascón, Alonso

"Estado, frontera y ciudadanía: el Septentrión entre el Antiguo Régimen y la formación de la nación mexicana”, tesis de doctorado en historia, Leiden, Holanda, Universidad de Leiden, 2013.

Estrada Michel, Rafael

Monarquía y nación entre Cádiz y Nueva España, México, Porrúa, 2006.

Flores, Manuel Antonio

Instrucción a su sucesor el señor Conde de Revillagigedo, México 26 de agosto de 1789, México, Imprenta Imperial, 1867.

García Martínez, Bernardo

“El espacio del (des)encuentro”, en CEBallos (comp.), 2001, pp. 19-51.

GonZÁlez, Judith

“Documentos de la Independencia en la Nueva Vizcaya”, en Textos de la Nueva Vizcaya, Chihuahua, Universidad Autónoma de Ciudad Juárez, año 1, núm. 2 (1993), pp. 1-83. 
González Alzate, Jorge

"Las milicias y la preservación del dominio español en Los Altos de Guatemala, 1973-1821", en Boletín, Asociación para el Fomento de los Estudios Históricos en Centroamérica, 26 (nov. 2006), http://www.afehc-historia-centroamericana.org/ index.php?action=bul_aff\&id=26

GonzÁlez Rodríguez, Luis et al.

Derechos culturales y derechos indígenas en la Sierra Tarabumara, Ciudad Juárez, Chih., Universidad Autónoma de Ciudad Juárez, 1994.

Gortari Rabiela, Hira de

"La organización política territorial. De la Nueva España a la primera república federal, 1786-1827”, en VÁzQuez (coord.), 2003, pp. 39-76.

Guedea, Virginia

"La historia política sobre el proceso de la independencia", en Ávila y GuedeA (coords.), 2010, pp. 41-64.

Hernández Silva, Héctor

"Las provincias de Sonora y Sinaloa, 1821-1825: el camino hacia el federalismo", en Vázquez (coord.), 2003, pp. 555-582.

Herrera Pérez, Octavio

"Autonomía y decisión federalista en el proceso de creación del estado libre y soberano de Las Tamaulipas”, en VÁzquez (coord.), 2003, pp. 417-444.

JÁUREgui, Luis

"Nuevo León, 1823-1825. Del Plan de Casa Mata a la promulgación de la constitución estatal”, en VÁzQuez (coord.), 2003, pp. 351-384. 
Jones, Oakah

Nueva Vizcaya: Heartland of the Spanish Frontier, Albuquerque, University of New Mexico Press, 1988.

Márquez, Zacarías (comp.)

Coloquio Camino Real. Bicentenario de la independencia de México, Chihuahua, Universidad Autónoma de Chihuahua, s.f http://www.uach.mx/extension_y_difusion/2012/07/31/coloquio_camino_real.pdf.

Morado Macías, César

"Nuevo León durante el proceso de independencia”, en MÁrQUEZ (comp.), s.f.

Navarro García, Luis

Don José de Gálvez y la Comandancia General de las Provincias Internas del norte de Nueva España, Sevilla, Escuela de Estudios Hispanoamericanos de Sevilla, 1964.

O'Gorman, Edmundo

Historia de las divisiones territoriales de México, México, Porrúa, 1968.

Orozco Orozco, Víctor

El estado de Chibuabua en el parto de la nación, 1810-1831, México, El Colegio de Chihuahua, Ichicult, Universidad Autónoma de Ciudad Juárez, Plaza y Valdés, 2007.

Ortiz Escamilla, Juan

Guerra y gobierno. Los pueblos y la independencia de México, 1808-1825, $2^{a}$ edición corregida y aumentada, México, El Colegio de México, Instituto de Investigaciones Dr. José María Luis Mora, 2014.

Pérez Herrero, Pedro

“El México borbónico: ¿un “éxito” fracasado?”, en VÁzQuez (coord.), 1992, pp. 109-151. 
Pietschmann, Horst

Las reformas borbónicas y el sistema de intendencias de Nueva España. Un estudio político administrativo, México, Fondo de Cultura Económica, 1996.

Río, Ignacio del

La aplicación regional de las reformas borbónicas, México, Universidad Nacional Autónoma de México, 1995.

Rodríguez O., Jaime E.

"Interpretaciones generales de las independencias", en Ávila y GuedEa (coords.), 2010, pp. 201-218.

Sánchez de Tagle, Héctor

Insurgencia y contrainsurgencia en Zacatecas, 1810-1813, Zacatecas, Universidad Autónoma de Zacatecas, LIX Legislatura del estado de Zacatecas, 2009.

Sheridan Prieto, Cecilia

"El primer federalismo en Coahuila", en VÁzquez (coord.), 2003, pp. 385-415.

Urías Hermosillo, Margarita

"Rarámuris en el siglo XVIII", en GonzÁlez Rodríguez, et al., 1994, pp. 73-126.

VÁzquez, Josefina Zoraida (coord.)

El establecimiento del federalismo en México, 1821-1827, México, El Colegio de México, 2003.

Interpretaciones del siglo XVIII mexicano. El impacto de las reformas borbónicas, México, Nueva Imagen, 1992.

Vizcaya Canales, Isidro

En los albores de la independencia. Las Provincias Internas de Oriente durante la Insurrección de don Miguel Hidalgo y Costilla, 1810-1811, Monterrey, Instituto Tecnológico de Monterrey, 1976. 
Weber, David J.

Bárbaros: Spaniards and their Savages in the Age of Enlightenment, New Haven y Londres, Yale University Press, 2005.

La frontera norte de México, 1821-1846. El sudoeste norteamericano en su época mexicana, México, Fondo de Cultura Económica, 1988. 
